Educación Física y Ciencia, vol. 23, n²4, e198, octubre-diciembre 2021. ISSN 2314-2561 Universidad Nacional de La Plata.

Facultad de Humanidades y Ciencias de la Educación.

Departamento de Educación Física

\title{
Educação Física Escolar na Pandemia da Covid-19: Experiências no Ensino Médio do Nordeste Brasileiro
}

\author{
Physical Education School in the Covid-19 Pandemic: Experiences in High School Class in Northeast Brazil
}

Educación Física Escolar en la Pandemia Covid-19: Experiencias en la Escuela Secundaria en el Noreste de Brasil

David Romão Teixeira

Universidade Federal do Recôncavo da Bahia (UFRB),

Centro de Formação de Professores, Brasil

david_romao@ufrb.edu.br

(iD) https://orcid.org/0000-0002-9482-745X

Vilas Bôas Junior Jaildo Calda dos Santos

Rede Estadual de Ensino da Babia - Colégio Estadual

Rômulo Galvão, Brasil

vilasboasjr1@gmail.com

iD https://orcid.org/0000-0002-4112-2309

Alexsandro Rabaioli Nunes Ribeiro

Rede Estadual de Ensino da Babia - Colégio Estadual

Santa Bernadete, Brasil

alexrabaioli@hotmail.com

(iD) https://orcid.org/0000-0002-6636-8428

Eunice Santos da Cruz

Rede Municipal de Ensino de Amargosa-Babia - Colégio

Municipal Almeida Sampaio, Brasil

eunicesantoscruz@gmail.com

(iD https://orcid.org/0000-0002-8073-5677

José Arlen Belträo

Universidade Federal do Recôncavo da Babia (UFRB),

Centro de Formação de Professores, Brasil

arleneducacaofisica@ufrb.edu.br

(iD) https://orcid.org/0000-0002-7344-0010

\section{Resumo:}

O objetivo deste artigo é compartilhar reflexões referentes às nossas experiências com o ensino da Educação Física no Ensino Médio desenvolvidas em dois colégios da rede pública do interior do Estado da Bahia, na primeira unidade escolar de 2021. A construção dos relatos utilizou como fonte de dados: i) os registros e relatórios dos núcleos do Programa de Residência Pedagógica de cada colégio; ii) os documentos oficiais que orientam o Ensino Médio; e iii) os registros de observação dos professores. Os relatos de experiência apontam aspectos importantes sobre o ensino da Educação Física no Ensino Médio em meio à pandemia do COVID-19, como: a) as dificuldades de fazer experimentos práticos no ensino remoto; b) a importância da elaboração de roteiros de estudo; c) a preocupação com o grande quantitativo de estudantes que não participam das atividades síncronas; d) as limitações de avaliar a aprendizagem. Concluímos que não é possível uma Educação Física escolar de qualidade no formato remoto, virtual,

\section{Recepción: 14 de agosto de 2021 | Aprobación: 09 Septiembre 2021 | Publicación: 01 Octubre 2021}


ou à distância, uma vez que não é possível garantir no Ensino Médio o aprofundamento dos conteúdos da Cultura Corporal sem a realização das experimentações práticas, em grupo, e sob a responsabilidade de um professor de forma presencial.

Palavras-chave: Educação Física, Ensino Médio, Ensino À Distância, Covid-19.

\section{Abstract:}

The purpose of this article is to share reflections regarding our experiences with teaching Physical Education at High School developed in two public schools in the interior of the State of Bahia, in the first school unit in 2021. The construction of the reports used the following as data source: i) the records and reports of the centers of the Pedagogical Residency Program of each school; ii) the official documents that guide High School; and iii) teacher observation records. The experience reports point out important aspects about the teaching of Physical Education at High School in the midst of the COVID-19 pandemic, such as: a) the difficulties in carrying out practical experiments in remote education; b) the importance of preparing study scripts; c) the concern with the large number of students who do not participate in synchronous activities; d) the limitations of evaluating learning. We conclude that it is not possible to provide quality school Physical Education in remote, virtual or distance format, since it is not possible to guarantee at High School the deepening of the contents of Body Culture without carrying out practical experiments, in groups, and under the responsibility of a teacher in person.

KEYWORDS: Physical Education, High School, Distance Learning, Covid-19.

\section{Resumen:}

El objetivo de este artículo es compartir reflexiones sobre nuestras experiencias con la enseñanza de la Educación Física en el Escuela Secundaria desarrolladas en dos escuelas públicas del interior del Estado de Bahía, en la primera unidad escolar de 2021. La construcción de los informes se utilizó como una fuente de datos: i) los registros e informes de los centros del Programa de Residencia Pedagógica de cada escuela; ii) los documentos oficiales que orientan al Escuela Secundaria; y iii) registros de observación del maestro. Los relatos de experiencia señalan aspectos importantes sobre la enseñanza de la Educación Física en el Escuela Secundaria en medio de la pandemia de COVID-19, tales como: a) las dificultades para realizar experimentos prácticos en educación a distancia; b) la importancia de preparar guiones de estudio; c) la preocupación por la gran cantidad de estudiantes que no participan en actividades sincrónicas; d) las limitaciones de evaluar el aprendizaje. Concluimos que no es posible brindar Educación Física escolar de calidad en formato remoto, virtual o a distancia, ya que no es posible garantizar en Escuela Secundaria la profundización de los contenidos de Cultura Corporal sin realizar experimentos prácticos, en grupos, y bajo la responsabilidad de un maestro en persona.

Palabras Clave: Educación Física, Escuela Secundaria, ducación A Di, Educación A Distancia, Covid-19.

\section{INTRODUÇÃO}

Desde o início do ano de 2020 a pandemia da COVID-19 assola o mundo, situação que agravou a crise econômica e social, resultado da desumana forma de produção da existência no regime capitalista. No Brasil este quadro é dramático, são mais de 500 mil mortes que poderiam ter sido evitadas se as medidas necessárias de combate à pandemia fossem adotadas. O que vivemos aqui, infelizmente, é o contrário, uma parcela dos governantes e principalmente o governo federal adotaram práticas mais próximas de uma sabotagem, o que tem permitido a ampliação da contaminação e mortes, mas que também amplia os níveis de miséria e fome no nosso país, impactando negativamente nos indicadores educacionais.

É neste cenário que iremos tratar da situação do ensino da Educação Física escolar no Brasil. Logo no mês de março de 2020 as aulas presenciais foram suspensas em todo território nacional, em abril o conselho pleno do Conselho Nacional de Educação (CNE) aprovou o parecer n. 05/2020, que tratou da reorganização dos calendários escolares e da possibilidade de cômputo de atividades não presenciais para fins de cumprimento da carga horária mínima (Brasil, 2020a). Essas mudanças acarretaram uma reestruturação forçada e desigual na organização do ensino escolar, que teve como central o incremento do Ensino Remoto Emergencial (ERE) na Educação Básica, que surgiu como uma medida temporária, mas que se prolonga até os dias atuais e ainda sem uma perspectiva oficial de retorno às atividades de ensino presenciais. Os transtornos que esta medida ocasiona à educação escolar, principalmente no que se refere às condições adequadas de ensino de qualidade, 
apresentam, em especial para a Educação Física escolar brasileira, um grande desafio: como garantir o ensino da Educação Física nas escolas públicas no formato remoto em plena pandemia?

Neste contexto de incertezas e de precariedades de condições estruturais que milhares de professores e professoras de Educação Física foram colocados a construírem alternativas e experiências de ensino, sem terem referências anteriores e produções científicas que abordassem esta situação inédita para a maioria. Neste artigo o objetivo é compartilhar reflexões referentes às nossas experiências desenvolvidas em dois colégios da rede pública do interior do Estado da Bahia, no nordeste brasileiro. Associamo-nos a todas as produções que se preocupam com a qualidade do ensino da Educação Física na atualidade e com os problemas do ensino a distância da Educação Física nas redes públicas de ensino.

\section{METODOLOGIA}

Este estudo tem como objeto de investigação as atividades de ensino da Educação Física realizadas em dois colégios estaduais que participam do Programa de Residência Pedagógica $(\mathrm{RP})^{1}$ em parceria com a Universidade Federal do Recôncavo da Bahia. Na atual edição deste programa federal, iniciado em outubro de 2020, 30 estudantes do curso de Licenciatura em Educação Física atuam em atividades de ensino sob a nossa supervisão enquanto professores dos colégios e sob nossa coordenação enquanto representante da universidade. Neste estudo, será analisada a primeira e segunda unidade do programa deste componente curricular, que aconteceu no ano de 2021, que foi de 15 de março a 19 de junho, com as turmas de primeiro, segundo e terceiro ano do Ensino Médio.

$\mathrm{Na}$ construção dos relatos das experiências utilizamos como fonte de dados os registros e relatórios produzidos pelos bolsistas e professores dos núcleos do RP de cada colégio, os documentos oficiais que orientam o Ensino Médio da rede estadual, os registros de observação da coordenação. Para subsidiar nossa discussão realizamos uma pesquisa no Google Scholar a procura de artigos que tratem da Educação Física escolar neste período de pandemia, na busca utilizamos o termo: Educação Física na pandemia. Realizamos uma primeira seleção pelos títulos, em seguida fizemos uma segunda seleção a partir da leitura total do artigo. Identificamos quatro artigos que estabelecem vínculos como o debate aqui empreendido. Para o tratamento e análise dos dados coletados recorremos à técnica de análise de conteúdo (Bardin, 1979), tendo como base teórica explicativa o materialismo histórico dialético (Marx, 2008; 2014; Marx \& Engels, 2007).

Adotamos neste estudo a abordagem Crítico-Superadora como referência teórica para a discussão sobre a concepção de Educação Física escolar. Esta abordagem surgiu no ano de 1992, na obra Metodologia do Ensino da Educação Física, também conhecida, na Educação Física brasileira, como Coletivo de Autores. Entre outras coisas, a referida abordagem defende que a Educação Física deve fazer parte do núcleo central do currículo da Educação Básica, uma vez que somente por meio das aulas de Educação Física escolar a maioria das crianças, jovens e adultos brasileiros terá a possibilidade de acessar o conhecimento sistematizado das atividades da Cultura Corporal,

[...] o conjunto de atividades humanas que surgem, historicamente, a partir das relações sociais de trabalho; se efetivam por ações e operações que buscam satisfazer as necessidades humanas de primeira ordem ou a elas relacionadas, e que ao longo do desenvolvimento do gênero humano assumem uma autonomia relativa em relação ao processo de trabalho, pois passam a se orientar por outros significados e sentidos que não estão necessariamente vinculados diretamente ao processo produtivo da vida humana. Buscam, na reprodução social, satisfazer outras necessidades humanas não menos importantes e que concorrem no processo de humanização do ser, em geral são valorizadas em si mesmas.

Elas se caracterizam por envolver ações e operações conscientes orientadas por motivos sociais, sejam eles advindos da competição, da exercitação, do agonismo, da sublimação, do lúdico, do estético, da expressão rítmica, e tantos outros que surgem no curso do processo histórico. Com efeito, os motivos das atividades da Cultura Corporal sofrem as determinações das condições materiais de existência (modo de vida), contudo, nesse processo, sempre haverá um motivo que irá assumir a função de momento predominante, que guiará a atividade numa dada direção. Na sociedade de classes sua socialização é restrita, uma vez que a mesma assume a forma de mercadoria, impondo uma formação limitada a maioria 
população da que não pode pagar para ter acesso, impedindo assim o pleno desenvolvimento das múltiplas potencialidades do ser social. O ensino escolar destas atividades passa obrigatoriamente pela apropriação dos fundamentos (técnico-objetal, axiológico e normativo/judicativo) destas atividades humanas onde é possível estabelecer uma relação consciente com a Cultura Corporal (Teixeira, 2018, p.49-50).

\section{A ATUALIDADE DA EDUCAÇÃO FÍSICA ESCOLAR NO ENSINO MÉDIO BRASILEIRO}

A política educacional brasileira adotada pós-golpe de estado em 2016, particularmente as medidas que implicam o ensino médio, alterou significativamente a estruturação e as bases orientadoras do último nível da educação básica. Com destaque para três instrumentos normativos que foram impostos ao arrepio da construção democrática pelo governo golpista de Michel Temer (2016-2018), com amplo apoio dos reformadores empresariais da educação, a saber, a Lei n. 13.415/2017, a Base Nacional Curricular Comum (BNCC) e as Diretrizes Curriculares Nacionais para o Ensino Médio (DCNEM) de 2018.

Dentre outras coisas, as alterações promovidas por esses dispositivos impactam significativamente a Educação Física, visto que seu status de componente curricular não está assegurado, e sua presença como disciplina no currículo deixou de ser obrigatória. As redes de ensino, ao regulamentarem e implementarem o novo ensino médio, poderão optar em manter a Educação Física como componente curricular ou ofertála como atividade escolar, seja no âmbito de outro componente curricular ou mesmo dissolvida na área de linguagens e suas tecnologias.

Os estudos e práticas da Educação Física integram o núcleo curricular destinado ao cumprimento da Base Nacional Comum Curricular (BNCC), ou seja, a formação comum. É necessário ressaltar que a carga horária destinada à formação comum sofreu importante redução e não se exige mais carga horária mínima a ser cumprida, apenas foi definida a carga horária máxima de 1.800 horas. Com efeito, caso se mantenham nas matrizes curriculares, os componentes curriculares que até então eram obrigatórios, como é o caso da Educação Física, via de regra, haverá redução das respectivas cargas horárias.

Além do tempo pedagógico, que notadamente tem repercussão na formação dos jovens que ingressarem nesse novo modelo, a perspectiva de conteúdo de Educação Física presente na BNCC privilegia conhecimentos tácitos em detrimento ao conhecimento científico (Beltrão, 2019).

Na prática, com essa medida, opera-se a retirada de conhecimento e o esvaziamento da formação escolar da juventude. Por outro lado, ao encaminhar o estudante para uma área de concentração ou formação profissional, antecipa-se a especialização deste jovem, em um processo formativo pobre e limitado. O tempo de formação profissional, nesse caso, é diminuto. Nessas circunstâncias, as formações profissionais estarão, tendencialmente, voltadas para o trabalho simples e de baixo valor agregado. Essas constatações indicam que o novo ensino médio tende a promover uma especialização precoce sob uma base (formação geral) precária/reduzida, em outros termos, apontam para uma formação unilateral radicalizada. O rebaixamento da formação básica pode significar a interposição de mais obstáculos para os jovens provenientes das classes populares acessar o ensino superior, expediente presente em quase toda a história do ensino médio, que a atual reforma revigora (Beltrão, 2019, p. 110).

O esvaziamento científico e a retirada completa ou parcial de conhecimentos constituintes de nossa cultura (corporal) têm impactos diferentes na juventude, a depender da sua condição social. Além do mais, agrava-se a crise enfrentada no ensino médio brasileiro, que sempre conviveu fortemente com uma dualidade estrutural (Taffarel \& Beltrão, 2109). Portanto, considerando que os jovens provenientes dos estratos dominantes da nossa sociedade reúnem condições para se apropriarem desses conhecimentos em outros espaços, ou mesmo nas suas escolas que, por sua vez, podem preservar esses conteúdos em seus currículos, as desigualdades historicamente observadas nesse nível de ensino, tanto do ponto de vista da quantidade (tempo de formação), quanto do ponto de vista da qualidade (tipo de conhecimento), tendem a aumentar.

O que está em disputa são os rumos da formação da juventude brasileira. É o estreitamento curricular e a interdição de qualquer perspectiva que vise uma formação integral. Justamente por isso, em todo o país, no 
momento em que redigimos esse artigo, professores de Educação Física resistem para impedir a extinção da Educação Física do currículo nessa importante etapa da Educação Básica (Freitas, 2021).

Reconhecemos a urgência de estudos científicos que contribuam com esta resistência ativa em curso na defesa da Educação Física no Ensino Médio, em especial por identificarmos que os conhecimentos da Cultura Corporal, objeto de ensino da Educação Física, assumem uma importância significativa e são imprescindíveis na formação dos estudantes. Como contraponto ao retrocesso presente nas reformulações curriculares, nos dispomos avançar teoricamente na elaboração que defende a Educação Física no Ensino Médio como um

[...] aprofundamento da sistematização do conhecimento. Nele, o estudante adquire uma relação especial com os
fenômenos ou objetos, que lhe permite refletir sobre eles. O estudante começa a perceber que há propriedades comuns e
regulares entre os objetos. Isso significa, por exemplo, que, para conhecer e explicar um fenômeno da realidade, tal como
a "relação do homem com a água [cultura corporal] 109", ele, além de constatar e organizar os dados sobre as propriedades
dos diferentes tipos de água [de formas sociais de atividades inerentes a cultura corporal] existentes e de conceituar a água [a
cultura corporal], precisa saber como, através de quais atividades humanas, com quais técnicas e instrumentos e de posse de
quais conhecimentos foi possivel ao homem, durante sua história, se relacionar de diferentes formas com a água [a cultura
corporal]. Dessa relação resultaram os conhecimentos náuticos [o esporte], da pesca [a ginástica], dos nados [o jogo], do
mergulho [a natação], dos animais marinhos [a luta], da geografia marinha [a dança], da física [a ginástica] e outros. O
estudante deverá saber onde buscar e como sistematizar o conhecimento teórico, ou seja, as explicaçôes da forma em que
os fenômenos se manifestam no real. Ele dá um salto qualitativo, quando estabelece as regularidades dos fenômenos. Neste
ciclo o estudante tem contato com a regularidade científica, podendo, a partir dele, adquirir condições objetivas para ser
produtor de conhecimento científico, quando submetido à atividade de pesquisa (Taffarel et al., 2010, p. 205).

A função precípua da escola é garantir a transmissão-assimilação dos conhecimentos científicos, filosóficos e artísticos, visando a elevação do padrão cultural e o desenvolvimento de uma reflexão pedagógica ampliada, que tem como "eixo a constatação, a interpretação, a compreensão e a explicação da realidade social complexa e contraditória" (Coletivo De Autores, 2012, p. 30). Dessa forma, possibilitando que nossos jovens, ao final da escolarização básica, sejam capazes de explicar a realidade complexa e nela intervir de maneira transformadora.

Nessa concepção curricular, de maneira articulada, os diferentes componentes curriculares possibilitariam o acesso a determinada dimensão da realidade, da cultura, contribuindo para a explicação da realidade no nível do pensamento do aluno (Melo, Lavoura, Taffarel, 2020). Nesse caso, nenhum componente curricular se justifica ou se legitima de maneira isolada, na medida em que só terá sentido pedagógico articulado com os demais (Coletivo De Autores, 1992).

Seria possível compreender nossa sociedade excluindo os conhecimentos relacionados às diferentes atividades da Cultura Corporal? Seria possível promover uma formação omnilateral sem os conhecimentos da Cultura Corporal? Entendemos não ser possível. Ademais, na concepção de currículo sinteticamente apresentada (Coletivo De Autores, 1992), a Educação Física é mais que justificável, é imprescindível, consistindo em um dos seus objetos nucleares (Beltrão, 2019).

Cabe ainda registrar que o ensino da Educação Física no ensino médio está ligado com a conquista da liberdade por parte dos estudantes, pois, ao se apropriar de conhecimentos sistematizados e técnicas mais elaboradas, o estudante "[...] adquire condições de objetivar-se de maneira cada vez mais livre e universal” (Beltrão, 2019, p. 224).

No voleibol, por exemplo, ao aprender a atacar a bola estando suspenso (fundamento/técnica - cortada), o sujeito conquista a possibilidade de participar de modo diferente e em uma situação para ele nova no jogo (liberdade). Por conseguinte, novas combinações passam a ser possíveis, necessidades são engendradas no sujeito (atacar estando em suspensão) e a partir desta conquista outras aprendizagens passam a ser factíveis. Promove-se, com isso, um ensino que está orientado para as objetivações representativas das máximas conquistas do gênero humano (Beltrão, 2019, p. 224).

Nas atuais circunstâncias, temos de um lado a perspectiva apontada pela BNCC, que visa fundamentalmente o desenvolvimento de competências e habilidades, para um agir prático imediato. De outro lado, propostas críticas que tentam se estabelecer na realidade contraditória brasileira, como é o caso da 
abordagem Crítico-Superadora. Nessa perspectiva, o ensino progressivo e sistematizado da Educação Física na educação básica estará orientado para que o jovem, ao final do ensino médio, tenha apreendido

[...] formas complexas das atividades da cultura corporal, o que possibilitará um agir cada vez mais elaborado, rico de determinações; além disso, será capaz de identificar, compreender e explicar os nexos lógico-causais dos fenômenos da cultura corporal na nossa sociedade (Beltrão, 2019, p. 221).

A correlação de forças, nesse momento, favorece a implementação do novo ensino médio e a concepção de educação e Educação Física presentes na BNCC. Mesmo com o advento da pandemia, as mudanças instituídas pelos instrumentos normativos supracitados seguem em curso pelo país, e sua implantação tornou-se ainda mais precária, já que desde o início de 2020 as redes de ensino públicas estão com atividades adaptadas em virtude da adoção do Ensino Remoto por conta do prolongamento da suspensão das aulas presenciais. Na Bahia não é diferente, a Secretaria de Educação da Bahia (SEC-BA), na jornada pedagógica de abertura do calendário 2021, descreveu como está acontecendo estas reformulações na sua rede de ensino:

No ano de 2020 se iniciou o processo de implementação do novo Ensino Médio em 544 escolas da rede estadual, configurando-se com uma nova arquitetura curricular composta por duas partes, a saber: a Base Nacional Comum Curricular e a Parte Flexível do Currículo composta por 05 (cinco) componentes curriculares: Projeto de Vida, Iniciação Científica, Produção Textual e Eletivas. Desta maneira, as unidades escolares piloto criaram as eletivas, fizeram a programação de professores e iniciaram o ano letivo ofertando o Novo Ensino Médio aos estudantes da $1^{\circ}$ Série.

As demais escolas da Rede Estadual, que iniciariam esse processo em 2021, também com as turmas de $1^{\text {a }}$ série, necessitaram ajustar o cronograma de implementação devido à situação pandêmica que vivenciamos, o que inviabilizou a formação com os gestores, coordenadores pedagógicos e professores sobre o Novo Ensino Médio. Essas escolas, que não estão no grupo piloto, em 2021, terão um ano de estudos, preparação e formação para o processo de transição curricular que se iniciará em 2022 (Bahia, 2021a).

É neste contexto que estamos responsáveis pela construção de duas experiências em dois colégios no interior do Estado da Bahia. Apresentaremos, a seguir, alguns apontamentos que estão em desenvolvimento neste marco histórico, que além de enfrentar os desafios próprios do Ensino Remoto Emergencial num período de pandemia, se esforçam em organizar uma proposição de ensino que fortaleça com argumentos teóricos a defesa da Educação Física no Ensino Médio.

\section{RELATO DAS EXPERIÊNCIAS COM O ENSINO REMOTO EMERGENCIAL NA EDUCAÇÃO FÍSICA ESCOLAR NA REDE ESTADUAL DA BAHIA}

No Estado da Bahia, a rede estadual suspendeu o seu calendário escolar em março de 2020 e só retornou o calendário oficial agora, no início do ano de 2021, em formato remoto. Em 2021, a rede estadual da Bahia conta com cerca de 800 mil estudantes, sua grande maioria no Ensino Médio e profissionalizante (Bahia, 2021b). Com a preocupação de partilhar nossas experiências, nesse artigo, apresentaremos os principais destaques das atividades de ensino realizadas em turmas do Ensino Médio de dois colégios do interior do Estado da Bahia, nos municípios de Amargosa e de Elísio Medrado, onde se desenvolve, em parceria com a Universidade Federal do Recôncavo da Bahia (UFRB), o programa Residência Pedagógica.

\subsection{Relato de experiência no núcleo do RP do município de Elísio Medrado - Bahia}

Esta experiência acontece no único colégio público que oferece o Ensino Médio no município. Nesse ano 516 estudantes foram matriculados, com oferta de Ensino Integral para as turmas de $1^{\circ}$ ano e $2^{\circ}$ ano; de Ensino Médio regular para as turmas do $3^{\circ}$ ano; e oferta da modalidade Educação de Jovens e Adultos (EJA), a maioria dos estudantes atendidos são da zona rural. 
A experiência será relatada a partir do nosso trabalho realizado nas turmas que lecionamos do $1^{\circ} \mathrm{e} 2^{\circ}$ ano do ensino integral e o $3^{\circ}$ ano regular, portanto, todas as turmas do turno matutino e vespertino. As únicas turmas do colégio que não fazem parte da experiência aqui analisada são as de Educação de Jovens e Adultos (EJA), por não ter oferta do componente curricular Educação Física nesse segmento formativo. Destarte, trabalhamos potencialmente com um quantitativo de 202 estudantes (sendo 90 estudantes do $3^{\circ}$ ano do Ensino Regular; 91 estudantes do $1^{\circ}$ ano e 111 do $2^{\circ}$ ano, ambos do Ensino Integral).

A retomada do calendário letivo em toda rede estadual de ensino na Bahia se deu a partir da implementação do currículo continuum, junção de duas séries em um ano letivo.

O planejamento da Secretaria da Educação do Estado indica a realização dos dois anos letivos, de 2020 e 2021, até o dia 29 de dezembro, com 1.500 horas aula. Serão três fases de atividades escolares. Após a etapa 100\% remota, será a vez da fase híbrida, com três dias da semana de aulas remotas e outros três de aulas presenciais e, por fim, a retomada das aulas $100 \%$ presenciais (Bahia, 2021).

Assim, os $3^{\circ}$ anos de 2020 passaram a ser $3^{\circ}$ ano especial; quem fazia $1^{\circ}$ ano em 2020 , em 2021 passou a estudar $1^{\circ} / 2^{\circ}$ ano; quem fazia o $2^{\circ}$ ano em 2020 , em 2021 passou a estudar $2^{\circ} / 3^{\circ}$ ano. Desta forma, as aulas de Educação Física foram organizadas considerando que: o $3^{\circ}$ ano especial tem uma $1 \mathrm{~h} /$ aula por semana; e as demais turmas com $2 \mathrm{~h}$ /aula por semana. Importante ressaltar que, durante a implementação do trabalho pedagógico, tivemos a colaboração de 9 residentes que fazem parte do programa de Residência Pedagógica da Universidade Federal do Recôncavo da Bahia (UFRB), subprojeto Educação Física; esses residentes trabalharam em conjunto conosco em todas as séries, sendo distribuídos em até 3 residentes por turma.

Juntamente com a equipe de residentes, iniciamos a nossa preparação e planejamento antes do anúncio da retomada do calendário letivo, que teve início em 15 de março de 2021. Desde outubro de 2020, já estávamos planejando e pensando de que forma organizaríamos o trabalho pedagógico frente ao desafio de minimizar os impactos da suspensão das aulas presenciais por mais de um ano e das desigualdades existentes entre as condições objetivas dos estudantes de acesso e permanência nas aulas virtuais.

Embora nós já tivéssemos nos preparando para o retorno das aulas, não tínhamos todas as respostas prontas quando o ano letivo 2020/2021 começou no dia 15 de março. Participamos, então, da pré-jornada pedagógica organizada pela secretaria de educação que durou uma semana, com lives transmitidas pelo Youtube. Nessa pré-jornada, foi explicado, de maneira genérica, aspectos sobre o funcionamento do ano letivo. Apesar disso, saímos dessa pré-jornada com mais dúvidas do que certezas.

Em seguida, foi feita a jornada pedagógica com a direção, coordenação e gestão do colégio. Mesmo durante a jornada pedagógica, não tínhamos muitas informações de como o processo do ensino remoto se sucederia. Foram inúmeras discussões sobre condição de acesso dos professores e estudantes, organização da unidade letiva, organização de uma semana de integração, metodologia do trabalho, planejamentos de unidade letiva e de aulas.

Durante o planejamento, foi necessário construir um plano para trabalhar com os estudantes que tinham acesso síncrono às aulas e um caderno de apoio e atividades para os estudantes que não têm acesso a internet e, portanto, não participavam das aulas síncronas. 67 estudantes não participaram das aulas síncronas, 135 participaram, mas grande parte de forma precária, utilizando celular com dados móveis, internet e equipamentos de baixa qualidade para acompanhamento das aulas de forma satisfatória.

A Secretaria de Educação do Estado da Bahia (SEC-BA) elaborou cadernos de apoio para aulas de Educação Física (Bahia, 2021d). Após uma avaliação do material junto com os residentes sobre o conteúdo elaborado, decidimos produzir nossos próprios cadernos, considerando os conteúdos que trabalhamos durante a primeira unidade. Optamos por não trabalhar com os cadernos da SEC-BA por estes apresentarem uma concepção acrítica, na medida em que não estabelecem relação do conteúdo exposto com as determinações sociais; a-histórico, pois não traz a história enquanto matriz científica e não compreende as atividades da Cultura Corporal como um patrimônio histórico da humanidade; e biologizante, pois 
considera, predominantemente, os aspectos biológicos do ser humano em detrimento dos aspectos sóciohistóricos.

Além do caderno de apoio para os estudantes que não têm acesso, utilizamos também as ferramentas disponibilizadas pela SEC-BA, a saber: Google Meet com condições de recursos ampliada, Google Classroom. De forma não oficial, utilizamos o Telegram. Nesse aspecto, vale ressaltar que, embora fossem disponibilizadas as ferramentas supracitadas, não foi dada para os professores e estudantes uma formação adequada para manuseio das ferramentas e aparelhos, e nem foi dado auxílio para pagar as despesas de energia e internet para os professores, por exemplo, para melhorar as condições de ensino e aprendizagem nas aulas. Tivemos que aprender a manusear as ferramentas sozinhos e utilizamos nossos próprios aparelhos e recursos financeiros para trabalhar.

Em relação aos conteúdos que foram tratados, trabalhamos com a Ginástica nos 1\%/2 anos; Tênis de Quadra com os $2^{\circ} / 3^{\circ}$ anos; e o Xadrez com o $3^{\circ}$ ano especial. Considerando estes conteúdos, estruturamos os conhecimentos centrais que são necessários para que os estudantes se aprofundem nos conteúdos destas atividades da Cultura Corporal, a saber: os fundamentos históricos, políticos, filosóficos e técnicos, além das principais regras e possibilidades de vivência com novas sínteses dos referidos conteúdos da Cultura Corporal na comunidade local em que vive cada estudante.

Por exemplo, destacamos as atividades sobre fundamentos do Tênis de Quadra em que fizemos uma discussão sobre o acesso a este esporte, do ponto de vista histórico, do alto custo financeiro para aquisições de seus materiais, das políticas públicas e dos espaços públicos disponíveis para prática deste esporte no município de Elísio Medrado - Bahia. Constatamos, a partir da análise dos elementos supracitados, que o Tênis de Quadra é um esporte restrito às classes dominantes; no entanto, decidimos produzir os nossos próprios materiais (raquete e bola) e vivenciamos os fundamentos do tênis dentro das possibilidades de cada estudante, de espaço na comunidade local e considerando também os limites impostos pelo trabalho remoto e pela pandemia. O produto final deste trabalho foi um conjunto de atividades (textos, vídeos, aulas) que nos permitiram avaliar o conhecimento apropriado pelos estudantes nesta unidade.

Por outro lado, não tivemos como acompanhar como se deu a experimentação prática e apropriação dos conhecimentos dos estudantes que não participaram das aulas síncronas por falta de equipamentos e internet, pois eles não só não têm condição de fazer vídeos, como também pegam o caderno de apoio em uma data e só devolvem no final da unidade. Nesse interstício entre o começo e o término da unidade, não tivemos contato com os estudantes que não têm condição de acesso.

Do ponto de vista formal, a metodologia adotada no processo de ensino e aprendizagem foi a alternância de aulas síncronas (em que estudante e professor estão online ao mesmo tempo e no mesmo espaço virtual) e assíncronas (em que professor e estudante não estão conectados ao mesmo tempo em um mesmo espaço virtual).

De modo geral, embora a presença dos estudantes nas aulas, na maioria das turmas, seja em quantidades significativas (144, ou seja, cerca de 70\%), a participação efetiva foi um dos limites durante o processo, pois muitos estudantes alegavam problemas com os aparelhos e internet, e frequentemente saiam da sala de aula; outro limite observado durante nossas aulas, foi em relação a discrepância no aproveitamento das atividades e, portanto, da aprendizagem, ou seja, os estudantes com melhores condições de acesso às aulas apresentaram melhor rendimento e aprenderam mais.

Outro fato que limitou o nosso trabalho foi a dificuldade de oferecer tarefas e exercícios práticos, sendo a Educação Física uma disciplina que necessita impreterivelmente de experimentos para melhor apropriação dos seus conteúdos. Muitos estudantes apresentavam resistência em elaborar vídeos experimentando os conteúdos da Cultura Corporal, segundo relato dos mesmos, por vergonha que sentia em se expor, timidez e até mesmo por falta de recursos tecnológicos e confiança para experimentar as tarefas e exercícios.

Além disso, observamos que o tempo necessário pedagogicamente para consolidação da aprendizagem foi muito curto, já que a unidade durou pouco mais de um mês e meio $(12 \mathrm{~h} /$ aulas para as turmas que têm 2 aulas 
por semana; para as que têm uma aula este número cai pela metade), em função da junção dos calendários escolares de 2020/2021 e a ampliação na quantidade de unidades.

Enquanto possibilidade, observamos que a utilização do caderno de apoio para auxiliar na aprendizagem dos estudantes foi um fator bastante positivo, pois possibilitou ao estudante ter um material sistematizado de orientação e estudos dos conteúdos da Educação Física, o que não tínhamos antes do ensino remoto, pela falta do livro didático em nossa área que não é disponibilizado em nossa rede de ensino. Além disso, a utilização de ferramentas tecnológicas para ajudar na organização do trabalho pedagógico também é outro elemento que devemos considerar, mesmo após o retorno das aulas presenciais, pois ajudaram a organizar, auxiliar o trabalho pedagógico e documentar as atividades, além de melhorar a comunicação com os estudantes para resolução e diálogo sobre problemas pontuais.

No que diz respeito à avaliação, tivemos como o principal critério avaliativo o nível de aproximação/ distanciamento dos estudantes ao eixo curricular da disciplina, além da verificação da participação e da frequência. Avaliamos cada estudante de forma processual, acompanhando os avanços durante as aulas e a partir das atividades realizadas.

No entanto, tivemos muita dificuldade em acompanhar o desenvolvimento dos estudantes que não participam das aulas síncronas (os não conectados) em função da falta de contato entre uma unidade e outra, porque os estudantes pegam as atividades no começo da unidade e só devolvem no final dela. Desta forma, não há avaliação durante o processo, mas somente ao final da unidade.

Destarte, verificamos, ainda, que houve avanços na aprendizagem dos estudantes, mas a apropriação se deu em nível muito menos satisfatório do que no ensino presencial, em função dos problemas que citamos acima e que se apresentaram no processo de ensino e aprendizagem e, também, a dificuldade de ter um acompanhamento mais próximo durante o tempo pedagógico. Outro fator importante que temos que destacar, é o fato dos estudantes, de um modo geral, não usar a câmera durante as aulas, dificultando assim a nossa percepção em saber se realmente eles estavam acompanhando o conteúdo da aula, mesmo que provocássemos a participação, a grande maioria não participa ativamente no momento da aula e esta é uma condição bastante limitante para o professor.

\subsection{Relato de experiência no núcleo do RP do município de Amargosa - Bahia}

O colégio onde desenvolvemos a experiência oferta atualmente o ensino fundamental II $\left(8^{\circ}\right.$ e $9^{\circ}$ ano $)$ e ensino médio ( $1^{\circ}$ ao $3^{\circ}$ ano), além da Educação de Jovens e Adultos (EJA) no noturno. Composto por um quadro de aproximadamente 1800 estudantes e 70 professores. Possui estudantes oriundos da zona rural que estudam, em sua grande maioria, pelo turno da manhã. Os alunos da zona urbana frequentam, na sua maioria, o turno vespertino. No noturno, abrange estudantes com idade adulta e trabalhadores.

Durante a primeira e segunda unidade foi trabalhado a Educação Física com 10 turmas, seis do terceiro ano do Ensino Médio ( $3^{\circ} \mathrm{A}, \mathrm{B}, \mathrm{C}, \mathrm{D}$ - matutino; $3^{\circ} \mathrm{A}$ e $\mathrm{B}$ - vespertino), e quatro turmas do segundo ano $\left(2^{\circ} \mathrm{A}\right.$, $\mathrm{B}$ - vespertino, $2^{\circ} \mathrm{D}, \mathrm{E}$ - matutino), totalizando, segundo os registros da caderneta escolar, aproximadamente 340 estudantes, 130 (40\%) destes participaram das aulas síncronas.

Num primeiro momento, foi realizado pelo colégio uma semana de integração que visou possibilitar reflexões pertinentes às problemáticas atuais, além de introduzir os estudantes nesse processo de ensino remoto. Após esse período, iniciamos as atividades específicas de cada componente. Na Educação Física, seguindo as recomendações/sugestões dos cadernos de apoio à aprendizagem disponibilizados/construídos pela Secretaria de Educação do Estado da Bahia (Bahia, 2021d), trabalhamos nas turmas de $3^{\circ}$ ano, com uma aula semanal, os conteúdos: a) Saúde, bem-estar e qualidade de vida: conceitos, princípios e relações com atividade física/ Conceito de Educação Física/conteúdos; b) Saúde, bem-estar e qualidade de vida: o sedentarismo e suas relações com a redução da atividade física e doenças. Nas turmas de $2^{\circ}$ ano matutino, com duas aulas semanais, foram trabalhados: a) Características dos esportes no tempo e no espaço/ Conceito 
de Educação Física e seus conteúdos; b) Contexto histórico; Diferença entre o esporte da escola e na mídia; c) Princípios do Treinamento desportivo.

Importante destacar que contamos com a participação/colaboração, por meio do estágio, dos residentes do curso de Licenciatura em Educação Física, da Universidade Federal do Recôncavo da Bahia, que a partir da quinta semana ficaram responsáveis pela regência das aulas em oito turmas até o final da segunda unidade, em 19 de junho de 2021, sob nossa supervisão.

Durante o período de análise foram ministradas 14 aulas para o $3^{\circ}$ ano e 28 aulas para o $2^{\circ}$ ano. Para organização do planejamento foi construído um roteiro de estudos/guia didático-pedagógico (e-book) com o passo a passo das atividades. Durante esse período, além das lives temáticas realizadas nas duas primeiras semanas de aulas, na Educação Física, realizamos ao longo do processo um encontro síncrono por semana (com duração de 50 minutos) no $3^{\circ}$ ano, no $2^{\circ}$ ano foram dois encontros por semana, um síncrono (com duração de 50 minutos) e outro assíncrono (com duração de 50 minutos), onde disponibilizamos podcast, vídeos, questionários, slides e outros materiais pedagógicos para revisão. Essa organização mesclada (síncrona e assíncrona) só foi possível no $2^{\circ}$ ano porque são duas aulas por semana, no $3^{\circ}$ ano existe apenas uma aula semanal, no entanto, mesmo não sendo obrigatório, também disponibilizamos os materiais de apoio à aprendizagem para os estudantes do $3^{\circ}$ ano.

As aulas em sua grande maioria foram teóricas, com poucos exercícios e tarefas práticas nas aulas realizadas de forma síncrona, devido à especificidade do conteúdo da Educação Física e dos limites do ensino remoto. Algumas tarefas e exercícios práticos foram disponibilizados para os alunos realizarem em casa e para, em seguida, registrarem os resultados e experiências nos roteiros de estudos. Além disso, foram organizadas algumas atividades dinâmicas, como questionários, uso do App Quizlet, atividades de resolução de problemas em grupo e debates temáticos com perguntas e respostas. Essas ferramentas tinham, na sua essência, a potencialidade de tornar as aulas mais interativas, pois dentro da plataforma era possível, por meio da gamificação que faz parte do contexto dos alunos, revisar conteúdos e aprofundar temáticas, essa organização flexível visou deixar as aulas mais atrativas e com um engajamento maior.

Dentre os elementos/ferramentas pedagógicas, podemos destacar a importância que os estudantes dão às aulas no Google Meet, o contato, mesmo que virtual, vem facilitando na formação de vínculos e no acompanhamento das aprendizagens. Os estudantes relataram nos roteiros de estudo que o momento mais importante de todo esse processo foi com o professor ao vivo para tirar dúvidas e interagir com os colegas. Outro instrumento que vem auxiliando são os grupos do aplicativo WhatsApp. Essa organização, por mais que em alguns momentos possa confundir os estudantes devido à quantidade de atividades, mensagens e informações, em muitos casos é o único contato síncrono possível, já que muitos estudantes não possuem internet de qualidade para acompanhar as aulas no Google Meet, assim, essa ferramenta possibilita o contato direto com o professor para tirar dúvidas e definir rotas do processo de aprendizagem, e por ele disponibilizamos os slides das aulas para auxiliar nos estudos individuais. O Google Classroom, que está em fase de adaptação, também é um espaço propício para envio dos materiais pedagógicos, avisos e organização das turmas.

Destacamos o roteiro de estudo como um instrumento pedagógico fundamental nesse atual contexto de suspensão de aulas presenciais, para alguns estudantes sem acesso à internet ele se constitui como o único meio de garantir a continuidade dos estudos neste formato de ensino remoto. Esses estudantes pegam o material impresso na escola em data pré-agendada pela gestão para evitar aglomerações. Após esse recebimento, o estudante tem um prazo para desenvolver as atividades de todas as disciplinas e retornar esse material para a escola para a futura avaliação dos professores.

Em relação à avaliação da aprendizagem dos estudantes com acesso à internet, foi construído um roteiro de estudo e entregue aos discentes para que toda semana eles possam responder no caderno, de acordo os conteúdos eram ministrados na aula síncrona. Ao final de cada unidade os mesmos encaminharam o material por e-mail, recebendo o retorno de suas produções. Além disso, foi avaliada a participação para 
os que podiam se fazer presentes nas aulas ao vivo, além dos projetos por área do conhecimento que estão sendo desenvolvidos no colégio, como a construção de contos que envolvem as disciplinas: Educação Física, Artes, Inglês e Português. Esse trabalho ao final do processo deverá gerar um e-book com as produções dos estudantes, afim de servir de material pedagógico sobre a temática.

Em geral, a maioria dos estudantes realizou os encaminhamentos solicitados nas tarefas e exercícios, foi possível identificar produções bem elaboradas e que estabeleceram as relações requeridas com os conteúdos discutidos nas unidades. Esse método é interessante, pois estimula que os estudantes reflitam e revisem os conteúdos vivenciados semanalmente. Um elemento dificultador é o acompanhamento das vivências práticas, mesmo que elas sejam pensadas e estimuladas durante a aula síncrona, não temos garantia de que nossos estudantes estão realizando e nem como estão realizando, principalmente porque as câmeras de grande parte deles ficam fechadas, seja porque os mesmos usam uma conexão de internet com baixa qualidade, seja pela vergonha de realizar os vídeos, e por outros agravantes que a tecnologia impóe. Nesse processo existem perdas irreparáveis, comparadas ao ensino presencial, para o aprendizado dos conteúdos da Educação Física.

\subsection{Preocupações emergentes}

Nos relatos de experiência aqui apresentados não foi possível observar ainda os impactos do Novo Ensino Médio no ensino da Educação Física conforme apresentado no início do artigo, o contexto pandêmico retardou em certa medida a reestruturação dos currículos, desta forma não podemos mensurar os efeitos desta reformulação em curso. Guardadas suas especificidades, os relatos apontaram alguns aspectos comuns que merecem destaque para refletirmos sobre o ensino da Educação Física no Ensino Médio no atual tempo histórico: a) as dificuldades de fazer experimentos práticos, uma especificidade da Educação Física; b) a importância dos materiais didáticos para o estudo (roteiros e cadernos); c) a preocupação com os estudantes que não podem participar das atividades síncronas; $d$ ) os limites do processo avaliativo da aprendizagem; e) a importância de incorporar as ferramentas das plataformas virtuais na organização do trabalho pedagógico do ensino presencial.

A natureza e a especificidade dos conhecimentos da Educação Física requerem obrigatoriamente que, para sua adequada apropriação, os estudantes façam experimentos e exercícios práticos, condição que não pode ser substituída por nenhuma outra tarefa. Num estudo recente com professores da rede pública do Ceará e do Rio Grande do Norte, foi também observada a dificuldade dos professores em elaborar as experimentações dos conteúdos por meio das tecnologias de informação, e apontou a preocupação neste momento de ensino remoto com uma ainda maior dissociação entre teoria e prática. Neste estudo identificou-se que houve um aumento de professores de Educação Física que buscam nas redes sociais exercícios e tarefas que atendam apenas a dimensão do saber fazer (Silva, Silva, Tinôco, Venâncio, Sanches Neto \& Araújo, 2021).

Pode-se afirmar que nas condições oferecidas pelo ensino remoto, o objeto de ensino é apropriado parcialmente. A experiência aqui relatada demonstrou que é possível tratar pedagogicamente de alguns elementos constituintes do objeto de ensino, entretanto, as aproximaçóes a esses elementos e a apreensão dos conhecimentos a eles relativos ocorrem precariamente. Por outro lado, é praticamente inviável promover um processo que resulte em aprendizagens de ações corporais cada vez mais complexas, requeridas nas práticas dos diferentes fenômenos que compõe a Cultura Corporal. Ou seja, nessas circunstâncias pretere-se os elementos nucleares de tais atividades.

Cabe ressaltar que para além da perda da especificidade da Educação Física, o ensino remoto concorre para descaracterizar o próprio ensino médio. Segundo Saviani (2005), no ensino médio deve-se enfrentar a contradição homem-trabalho, que é ocultada na concepção burguesa de educação.

A contradição entre o homem e o trabalho contrapóe o homem, enquanto indivíduo genérico, ao trabalhador. Nesse contexto, o trabalho, que constitui a atividade especificamente humana por meio da qual o homem produz a si mesmo, se converte, para o trabalhador, de afirmação da essência humana, em negação de sua humanidade. O trabalho, fonte criadora 
da existência humana, elemento de humanização da natureza que liberta a humanidade do jugo natural, se constitui, na sociedade burguesa, em elemento de degradação e escravização do trabalhador. Em consequência, a educação que a burguesia concebeu e realizou sobre a base do ensino primário comum não passou, nas suas formas mais avançadas, da divisão dos homens em dois grandes campos: aquele das profissões manuais para as quais se requeria uma formação prática limitada à execução de tarefas mais ou menos delimitadas, dispensando-se o domínio dos respectivos fundamentos teóricos; e aquele das profissóes intelectuais para as quais se requeira domínio teórico amplo a fim de preparar as elites e representantes da classe dirigente para atuar nos diferentes setores da sociedade (Saviani, 2005, p. 232).

A relação estabelecida entre educação-trabalho se altera ao longo da educação básica. Enquanto no ensino fundamental o princípio do trabalho é imanente, e a relação é implícita e indireta, no ensino médio essa relação é explícita e direta. Portanto, a relação entre conhecimento e atividade prática deverá ser tratada de maneira explícita e direta, já que "[...] o saber tem uma autonomia relativa em relação ao processo de trabalho do qual se origina. O papel fundamental da escola de nível médio será, então, o de recuperar essa relação entre o conhecimento e a prática do trabalho" (Saviani, 2007, p. 160).

Nessa concepção, o central do ensino médio é desenvolver um processo educativo que possibilite dominar os elementos básicos e gerais do conhecimento que contribuem para o processo de trabalho, mas também como esse conhecimento se converte em potência material no processo produtivo (Saviani, 2007). A superação da contradição homem-trabalho no ensino médio passa "[...] pela tomada de consciência teórica e prática do trabalho como constituinte da essência humana para todos e cada um dos homens”. O que é possível pela adoção da ideia de politecnia, (Saviani, 2005, p. 234).

A ideia de politecnia compreende o processo de trabalho constituído por ações manuais e intelectuais indissociáveis, uma unidade indissolúvel. Dessa forma, perspectiva a superação da dicotomia entre trabalho manual e trabalho intelectual, entre instrução técnica e formação geral (Saviani, 2003). Para tanto, os estudantes, necessariamente, terão experiências na manipulação dos processos básicos de produção (Saviani, 2007) e a apropriação de "[...] princípios científico-tecnológicos e sócio-históricos que organizam a produção e as relação sociais modernas [...]” (Ramos, 2006, p. 139). Segundo Beltrão (2019), no campo da Cultura Corporal, para além de abordarmos sua inserção no processo produtivo de mercadorias, trataríamos da aplicação da ciência na produção e reprodução de práticas corporais, em outros termos, "[...] como seria possível articular o conhecimento teórico e científico na experiência das práticas corporais durante as aulas" (Beltrão, 2019, p. 229). Essa articulação é essencial, vez que a cisão entre ações intelectuais e práticasmanuais descaracterizam as atividades da cultural corporal. Por sua vez, a aplicação de conhecimentos científicos amplia as possibilidades de objetivações dos sujeitos e enriquecem a própria atividade de determinações.

Se em determinado momento da história da Educação Física (e em certa medida ainda na atualidade) as aulas desse componente curricular eram predominantemente ocupadas por atividades práticas mecanizadas e empobrecidas de significações, promover uma transformação no sentido de sucumbir com as possibilidades reais e efetivas de experimentos corporais, como observações na experiência de ensino remoto, resultaria na manutenção de uma educação vigorosamente unilateralizada.

Em estudo com professores da rede privada de ensino de Cuiabá - MT, identificou-se nos relatos dos professores as dificuldades durante as aulas pela resistência dos estudantes de usar as câmeras nas aulas on-line, e que isto é mais acentuado nos estudantes mais velhos (Godoi, Kawashima \& Gomes, 2020). Estes estudos corroboram com o que nossas experiências apontaram neste aspecto, reforçando que as condições para tratar desta dimensão não estão à disposição nem dos professores e muito menos da maioria dos estudantes, a ausência, por exemplo, do uso das câmeras impossibilita averiguar se os estudantes estão realizando os exercícios indicados, e o mais importante, se estão fazendo da forma correta. Esta situação corriqueira nesta forma de ensino remoto é um entrave para o aprofundamento da sistematização dos conhecimentos da Cultura Corporal, que é o mínimo esperado na Educação Física no Ensino Médio.

Um elemento de destaque positivo que aparece nas nossas experiências foi a disponibilidade de material didático de apoio para os estudos da Educação Física, mesmo identificando divergências na discussão do 
conteúdo dos materiais, todos os envolvidos reconheceram a importância de existirem os livros didáticos, roteiros, ou cadernos específicos para o ensino das atividades da Cultura Corporal, principalmente para o aprofundamento necessário no Ensino Médio. Na rede estadual da Bahia foi uma novidade que apareceu para auxiliar no ensino remoto, na avaliação dos professores e estudantes as redes devem adotar livros didáticos como recurso pedagógico mesmo no retorno das aulas presenciais. Contudo, no caso em particular do livro produzido pela rede estadual da Bahia, seu conteúdo deve ser rigorosamente analisado, no sentido de apontar os seus limites e possibilidades, contribuindo para a produção de uma nova versão, que aborde os fenômenos da cultural corporal de maneira histórico-crítica e melhor corrobore com a elevação da capacidade teórica dos nossos estudantes.

Os livros didáticos podem cumprir um papel importante na atual situação, uma vez que é o único recurso que os estudantes que estão impossibilitados de acessar as aulas on line estão tendo para o estudo individual. Esta situação é a mais preocupante, muitos estudantes estão sem ter aulas, por não terem as condições objetivas para aulas síncronas, efetivamente estão tendo que aprender sozinhos, algo que precisa ser urgentemente resolvido, enquanto não retorna as atividades presenciais. Numa investigação realizada em 2020, sobre a adesão dos estudantes às atividades remotas na rede pública do Ceará, do Rio Grande do Norte, e da Paraíba, foi identificado um expressivo número de estudantes que não responderam as atividades remotas, algo por volta de $71,45 \%$, o que segundo os autores "pode representar a dificuldade no acesso as tecnologias e/ou conhecimentos técnicos básicos” (Silva, Pereira, Oliveira, Surdi \& Araújo, 2020, p. 68). Nas nossas experiências ainda não foi possível avaliar o retorno das tarefas encaminhadas por este público de estudantes, mas reconhecemos que deve ser uma preocupação imediata, já que representa um universo significativo de estudantes, representando nos colégios que desenvolvemos as experiências algo entre 30 a $50 \%$ do universo estudantil.

A nossa experiência aqui apresentada expôs a precária qualidade do ensino no formato remoto, isto fica explícito nas dificuldades de acompanhar e avaliar a aprendizagem dos estudantes. No caso especial da Educação Física no Ensino Médio, os problemas existentes antes da pandemia se agravaram, a pequena carga horária semanal de aulas no formato remoto prejudicou ainda mais o ensino dos conteúdos, e piorou as condições de avaliar a aprendizagem, principalmente pelas limitações no campo da interação e acompanhamento das tarefas e exercícios, ficando limitados a avaliar aspectos apenas indiretos da aprendizagem.

Por fim, outro aspecto que destacamos é que as ferramentas do ensino remoto são instrumentos que poderão ser incorporadas no ensino presencial, como recurso complementar e de apoio. O ensino presencial pode e deve ser melhorado, mas não é possível de ser substituído. A comunidade escolar foi pressionada de forma aligeirada para o uso das ferramentas do ensino remoto, muitas ainda subutilizadas por falta de maior conhecimento de suas funcionalidades e da ausência dos equipamentos de qualidade adequada, mas é acentuado pelos professores que estes recursos servirão para aprimorar a qualidade das aulas presenciais. Esta constatação foi observada também no estudo de (Godoi, Kawashima \& Gomes, 2020), e nas investigações feitas por (Coelho \& Marques, 2020) com estudantes da rede estadual do Rio de Janeiro.

\section{CONSIDERAÇÕES FINAIS}

Neste momento nossas considerações são preliminares, já que ainda estamos no início desta conturbada experiência de Ensino Remoto. Entretanto, é possível apresentar alguns apontamentos, dentre eles, que não é possível desenvolver um ensino de qualidade no formato remoto, virtual, ou a distância, principalmente relacionado à Educação Física, uma vez que não é possível garantir a apropriação do seu conteúdo escolar sem a realização de aulas presenciais, em grupo, e sob a responsabilidade de um professor, especialmente no Ensino Médio. 
Outra constatação possível de ser feita é que a precariedade do ensino se acentua com o trabalho remoto, em especial no Brasil. É consensual que as condições de trabalho dos professores pioraram, seja pelo aumento da jornada de trabalho, seja pela ausência de suporte material e financeiro por parte dos governos, os professores estão responsáveis pelo custeio de todas as despesas que o ensino remoto exige.

Para a defesa da permanência da Educação Física no currículo obrigatório do Ensino Médio a suspensão das atividades presenciais é um grande obstáculo, no formato remoto o ensino da Educação Física é mais reduzido e empobrecido, o que favorece o projeto do Novo Ensino Médio. Não vislumbramos alternativas positivas para o ensino da Educação Física por meio das atividades pedagógicas remotas, esse ensino em curso cumpre a função de reduzir danos apenas. Na atualidade, as problemáticas da Educação Física escolar que já eram enfrentadas antes da pandemia ganharam maior relevância, o que estava ruim, ficou pior. Ao reivindicar o retorno das aulas presenciais, o fazemos para exigir não o ensino presencial anterior, mas sim um presencial de qualidade.

Reconhecemos os limites das nossas contribuições, mas também entendemos que, neste momento de calamidade mundial, é imprescindível o compartilhamento científico, mesmo com análises preliminares, para poder subsidiar a construção teórica necessária para viabilizar a superação dos problemas contemporâneos. Nesta empreitada, constatamos a importância da ação conjunta das instituições públicas de ensino, como no caso aqui apresentado pelo Programa Residência Pedagógica, onde envolve a universidade e as escolas públicas numa mesma empreitada em defesa do ensino público de qualidade.

Os dados atualmente disponíveis permitem apontar que é preciso exigir que sejam urgentemente garantidas as condições necessárias e seguras para o retorno às aulas presenciais, o prolongamento desta forma de ensino remota irá gerar graves prejuízos para atual geração de crianças e jovens.

\section{REFERÊNCIAS}

Bahia. (2021a). Ensino Médio. Recuperado de: http://jornadapedagogica.educacao.ba.gov.br/caixa-de-ferramentas/e nsino-medio/

Bahia. (2021b). Rui anuncia pagamento de quinta parcela do Vale-alimentação Estudantil. Recuperado de: http://estu dantes.educacao.ba.gov.br/noticias/rui-anuncia-pagamento-de-quinta-parcela-do-vale alimentacao-estudantil.

Bahia. (2021c). Governador anuncia início do ano letivo na rede estadual de ensino. Recuperado de: http://escolas.edu cacao.ba.gov.br/noticias/governador-anuncia-inicio-do-ano-letivo-na-rede-estadual-de-ensino.

Bahia. (2021d). Ensino Médio - Educação Física. Recuperado de: http://www.educacao.ba.gov.br/midias/document os/ensino-medio-educacao-fisica.

Bardin, L.(1979). Análise de conteúdo. Lisboa: Edições 70.

Beltrão, J. A. (2019). Novo ensino médio: o rebaixamento da formação, o avanço da privatizaçãoe a necessidade de alternativa pedagógica crítica na educação física. (Tese Doutorado em Educação - Faculdade de Educação, Universidade Federal da Bahia), Salvador.

Beltrão, J. A.; Teixeira, D. R; Taffarel, C. N. Z; Melo, F. D. A.; Tranzilo, P. J. R. (2020). A Ofensiva dos Reformadores Empresariais da Educação em Tempos de Pandemia: o desastre social como oportunidade para avançar na privatização da Educação Básica. In: A. M. da C. Uchoa.et al.(Orgs.) Diálogos criticos, volume 3: EAD, Atividades remotas e o ensino doméstico: cadê a escola? (pp.153-194) [recurso eletrônico] Porto Alegre,RS: Editora Fi.

Brasil. Ministério da Educação, Conselho Nacional De Educação (2020a). Conselho Pleno (CP). Parecer $C N E / C P$ n. 5, de 28 de abril de 2020. Assunto: Reorganização do Calendário Escolar e da possibilidade de cômputo de atividades não presenciais para fins de cumprimento da carga horária mínima anual, em razão da Pandemia da Covid-19. Aprovado em 28 de abril de 2020. Recuperado de: http://portal.mec.gov.br/conselho-nacional-de-educacao/atos-normativos--sumulaspareceres-e-resolucoes/ 33371-cne-conselho-nacional-de-educacao/90771-covid-19. 
Brasil. Ministério da Educação, CAPES. (2020b). Programa de Residência Pedagógica. Recuperado de: https://www.g ov.br/capes/pt-br/acesso-a-informacao/acoes-e-programas/educacao-basica/programa-residencia-pedagogica.

Coelho, C. G, Xavier, F. V. F, \& Marques, A. C. G. (2020). Educação física escolar em tempos de pandemia da covid-19: a participação dos alunos de ensino médio no ensino remoto. Intercontinental Journal on Physical Education, 2 (3), e2020018. Recuperado a partir de: http://www.ijpe.periodikos.com.br/article/5f87ba8e0e882579783901 $\mathrm{ab}$

Coletivo de Autores. (1992). Metodologia do Ensino de Educação Física. São Paulo: Cortez.

Freitas, L. C. (2021). Educação Física está sendo "apagada" no Ensino Médio [mensagem no blog Avaliação Educacional]. Recuperado de: https://avaliacaoeducacional.com/2021/06/09/educacao-fisica-esta-sendo-apag ada-no-ensino-medio/

Godoi, M., Kawashima, L. B., Gomes, L. A. (2020). “Temos que nos reinventar”: os professores e o ensino da educação física durante a pandemia de COVID-19. Dialogia, São Paulo, 36, set./dez, p. 86-101. https://doi.org/10.558 5/dialogia.n36.18659.

Marx, K. (2008). Contribuição à crítica da economia politica. 2a ed. São Paulo: Expressão Popular.

Marx, K. (2014) O Capital: critica da Economia Política. Livro I. 32a edição. Rio de Janeiro: Civilização Brasileira.

Marx, K; Engels, F. (2007). A ideologia alemã. São Paulo: Boitempo.

Melo, F. D. A., Lavoura, T. N., Taffarel, C. N. Z. (2020). Ciclos de escolarização e sistematização lógica do conhecimento no ensino crítico-superador da educação física: contribuições da teoria da atividade. Revista Humanidades e Inovação. . (10), p. 117-134.

Ramos, M. N. A(2006). Pedagogia das Competências. autonomia ou adaptação? 3a ed. São Paulo: Cortez.

Saviani, D. (2003b). O choque teórico da politecnia. Trabalho, Educação e Saúde, Rio de Janeiro, 1 (1), p. 131-152.

Saviani, D. (2005). Educação Socialista, Pedagogia Histórico-Crítica e os desafios da sociedade de classes. In.: Lombardi, J. C.; Saviani, D. (Orgs.). Marxismo e Educação: debates contemporâneos. Campinas: Autores Associados.

Saviani, D. (2007). Trabalho e educação: fundamentos ontológicos e históricos. Revista Brasileira de Educação, 12 (34), p. 152-180, jan./abr..

Silva, A. J. F. da, Pereira, B. K. M., Oliveira, J. A. M. de, Surdi, A. C. e Araújo, A. C. de. (2020). A adesão dos alunos às atividades remotas durante a pandemia: realidades da educação física escolar. Corpoconsciência, 24 (2), p. 57-70, mai./ ago.

Silva, A. J. F. da, Silva, C. C. da, Tinoco, R. de G., Venâncio, L., Sanches Neto, L., Araújo, A. C. de. (2021). Desafios da Educação Física Escolar em tempos de pandemia: notas sobre estratégias e dilemas de professores(as) no combate à Covid-19 (Sars-Cov-2). Cenas Educacionais. Caetité - Bahia - Brasil, 4, (10618), p.1-27.

Taffarel, C. N. Z et. al. (2010). Cadernos didáticos sobre educação no campo. Universidade Federal da Bahia: Salvador.

Taffarel, C. N. Z.; Beltrão, J. A. (2019). Destruição de forças produtivas e o rebaixamento da formação da classe trabalhadora: o caso da reforma e da BNCC do ensino médio. Germinal: Marxismo e Educação em Debate, Salvador, 11 (1). p. 103-115.

Teixeira, D. R. (2018). Educação Física na pré-escola: contribuiçôes da abordagem critico-superadora. (Tese Doutorado - Universidade Federal da Bahia. Faculdade de Educação) Salvador-BA.

\section{Notas}

1 O Programa de Residência Pedagógica é uma das ações que integram a Política Nacional de Formação de Professores e tem por objetivo induzir o aperfeiçoamento da formação prática nos cursos de licenciatura, promovendo a imersão do licenciando na escola de educação básica, a partir da segunda metade de seu curso (BRASIL, 2020b). 